\title{
Risk factors of metachronous brain metastasis in patients with EGFR-mutated advanced non-small cell lung cancer
}

\author{
Wen Ouyang ${ }^{1 \dagger}$, Jing $\mathrm{Yu}^{1 \dagger}$, Yan Zhou ${ }^{1 \dagger}$, Jing $\mathrm{Hu}^{1}$, Zhao huang ${ }^{1}$, Junhong Zhang ${ }^{1,2,3^{*}}$ and Conghua Xie $\mathrm{X}^{1,2,3^{*}}$ (D)
}

\begin{abstract}
Background: NSCLC patients with EGFR mutation were at a higher incidence of developing brain metastasis (BM). Patients with BM are associated with high mortality. Reducing BM incidence becomes increasingly significant for NSCLC patients to achieve prolonged survival. The aim of the study was to explore the possible risk factors of developing metachronous BM during EGFR-TKIs treatment, and to identify the potential candidates for prophylactic cranial irradiation $(\mathrm{PCl})$ or the first-line Osimertinib treatment.
\end{abstract}

Methods: A total of 157 consecutive EGFR-mutated advanced NSCLC patients without BM at initial diagnosis in our institution from 2012 and 2018 were retrospectively reviewed. Comparisons of OS were performed based on BM status. The cumulative incidence of metachronous BM was calculated by the Kaplan-Meier method, and the independent risk factors of metachronous BM were investigated by multivariate analysis.

Results: Patients developing metachronous BM had worse survival (mOS: 22.1 months) than patients notdeveloping BM (mOS: 44.8 months). Moreover, the multivariate analysis indicated that age $\leq 49$ years $(P=0.035)$, number of extracranial metastases $(P=0.013)$, and malignant pleural effusion $(P=0.002)$ were independent risk factors of metachronous BM. Furthermore, the 1-year actuarial incidence of developing metachronous BM in patients with no risk factor $(n=101)$, 1 risk factor $(n=46)$, and 2 risk factors $(n=10)$ were $7.01,14.61$, and $43.75 \%$, respectively $(P<0.001)$.

Conclusions: Patients developing metachronous BM during EGFR-TKIs treatment have worse outcomes. Our results suggested that EGFR-mutated advanced NSCLC patients with $\geq 1$ risk factors were candidates for $\mathrm{PCl}$ or the first-line Osimertinib treatment.

Keywords: Non-small cell lung cancer, Epidermal growth factor receptor, Brain metastases, Risk factor

\section{Background}

Lung cancer is the leading cause of cancer death all over the world [1]. Among them, $80-85 \%$ of patients are diagnosed as non-small cell lung cancer (NSCLC) [2]. Despite the presence of the blood-brain barrier (BBB), brain

\footnotetext{
* Correspondence: zjhzhongnan@163.com; chxie_65@whu.edu.cn

'Wen Ouyang, Jing Yu and Yan Zhou contributed equally to this work. 'Department of Radiation and Medical Oncology, Zhongnan Hospital of Wuhan University, 169 Donghu Road, Wuchang District, Wuhan 430071, Hubei, China

Full list of author information is available at the end of the article
}

is still a frequent site of NSCLC metastasis. 10\% of NSCLC patients present brain metastasis (BM) at their initial diagnosis, and $40-50 \%$ of patients develop metachronous BM during the course of the disease [3]. Patients with $\mathrm{BM}$ are associated with high mortality, poor prognosis, neurocognitive and life quality deficits [4]. Epidermal growth factor receptor tyrosine kinase inhibitors (EGFR-TKIs) largely improved the survival of EGFR-mutated advanced NSCLC patients [5-7]. Similarly, EGFR-mutated NSCLC patients with BM had a

(c) The Author(s). 2020 Open Access This article is licensed under a Creative Commons Attribution 4.0 International License, which permits use, sharing, adaptation, distribution and reproduction in any medium or format, as long as you give appropriate credit to the original author(s) and the source, provide a link to the Creative Commons licence, and indicate if changes were made. The images or other third party material in this article are included in the article's Creative Commons licence, unless indicated otherwise in a credit line to the material. If material is not included in the article's Creative Commons licence and your intended use is not permitted by statutory regulation or exceeds the permitted use, you will need to obtain permission directly from the copyright holder. To view a copy of this licence, visit http://creativecommons.org/licenses/by/4.0/. The Creative Commons Public Domain Dedication waiver (http://creativecommons.org/publicdomain/zero/1.0/) applies to the data made available in this article, unless otherwise stated in a credit line to the data. 
worse median OS of 25.1 months than the patients without BM (30.2 months) [8]. Whereas it was reported that NSCLC patients with EGFR mutation were at a higher incidence of developing BM than EGFR wild type [9-11]. Therefore, prevent the occurrence of metachronous BM becomes increasingly significant for EGFRmutated advanced NSCLC patients to achieve prolonged survival.

How to reduce incidence of developing metachronous BM for EGFR-mutated advanced NSCLC patients? Firstly, prophylactic cranial irradiation (PCI) is a technique that delivers radiation therapy (RT) to the whole brain to prevent BM occurrence. It was reported to significantly reduce incidence of metachronous BM and improve overall survival (OS) in patients with limitedstage small cell lung cancer (SCLC) [12]. Whereas the results of RTOG-0214 on the effects of PCI in localized NSCLC patients indicated that PCI could reduce BM incidence, but failed to improve OS [13] and leaded to decline in immediate and delayed recall [14]. Interestingly, the 10-years update of RTOG-0214 showed that only patients non-operatively treated have an improved OS $(P=0.026, \mathrm{HR}=1.42,95 \% \mathrm{CI}: 1.04-1.94)$ and DFS $(P=$ 0.014), implying that PCI might just benefit NSCLC patients with higher risk of BM. Secondly, Osimertinib is an oral, irreversible third-generation EGFR-TKIs with higher penetration in central nervous system (CNS) [1517]. FLAURA study showed the lower frequency of CNS progression in the Osimertinib group than in the standard EGFR-TKIs group [17]. However, the first-line Osimertinib treatment for EGFR-mutated advanced NSCLC patients is not widely available in most developing countries due to its high cost. Therefore, it is higher costeffective to apply the first-line Osimertinib treatment for EGFR-mutated NSCLC patients with higher risk of BM. These findings prompted us to identify population subsets with higher risk of $\mathrm{BM}$, who are candidates for PCI or the first-line Osimertinib treatment.

Consequently, we established a retrospective singleinstitutional database including consecutive patients with EGFR-mutated advanced NSCLC between January 2012 and June 2018, to evaluate the impact of BM status on OS, to explore the possible risk factors for developing metachronous BM during the course of first-generation EGFR-TKIs therapy, and to identify the potential candidates for PCI or the first-line Osimertinib treatment.

\section{Methods}

\section{Patients}

The flow chart of patient enrollment was shown in Fig. 1. Between January 2012 and June 2018, a total of 157 consecutive EGFR-mutated advanced NSCLC patients without $\mathrm{BM}$ at initial diagnosis were reviewed at the Department of Radiation and Medical Oncology, Zhongnan
Hospital of Wuhan University. Our inclusion criteria are: (1) NSCLC was confirmed by cytology (14 pts), or histology (143 pts) (World Health Organization, WHO); (2) EGFR mutations were detected by real-time quantitative PCR (ARMS, 126 pts) or Next Generation Sequencing (NGS, 31 pts), using histological or cytological specimens from primary or metastatic lesions; (3) The disease was clinically diagnosed as stage IIIB (10 pts)-IV (147 pts) (American Joint Committee on Cancer, the 7th Edition); (4) Patients had negative results of enhanced magnetic resonance imaging (MRI, 149 pts) or computed tomography (CT, 8 pts) scans of brain before initial treatment; (5) Patients were treatment naive for EGFR-TKIs treatment. All patients received comprehensive assessments within 1 month before treatment, including physical and pathological examination, EGFR mutation test, and TNM stage evaluation.

\section{Treatment and follow up}

Among the 157 patients without BM at initial diagnosis, 24 patients received chemotherapy as their first-line therapy, and the other 133 patients received EGFR-TKIs treatment initially. EGFR-TKIs (gefitinib, erlotinib, or icotinib) were continuously administered until progression of disease (PD) or intolerable side effects. Treatment beyond PD was allowed on the judgement of continuously clinical benefit by the oncologists.

Follow-up examinations were performed every 2 months, including thoracic and abdominal CT scan, brain MRI scan. Progression-free survival (PFS) was defined as the time from EGFR-TKIs treatment to PD (including local, regional, or distant progression) or death from any cause. OS was defined as the time from EGFR-TKIs treatment to death from any cause. Brain-metastasis-free survival (BMFS) was defined as the time from EGFR-TKIs treatment to BM occurrence. Treatment responses were evaluated by the response evaluation criteria in solid tumors as complete response $(\mathrm{CR})$, partial response $(\mathrm{PR})$, stable $(\mathrm{SD})$, and progression (PD).

\section{Statistics}

All statistical analyses were conducted using Statistical Package for Social Scientists (SPSS/Windows, Version 22.0, SPSS Inc., Chicago, USA). Descriptive statistics were used for categorical variables (frequency and percentage) and continuous variables (median and range). The cumulative incidence of BM and survival were calculated by the Kaplan-Meier method with $95 \%$ confidence intervals (CIs). Univariable and multivariable Cox regression analyses were performed to explore the risk factors of metachronous BM. The multivariable Cox regression analysis simultaneously included factors that had shown associations $(P<0.100)$ in the univariable 
IIIB-IV stage patients with non-small

cell lung cancer (NSCLC) from

January 2012 and June 2018

$\mathrm{N}=1,579$

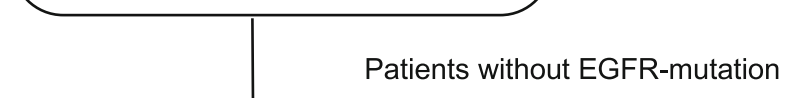

Exclude $\mathrm{n}=1,350$

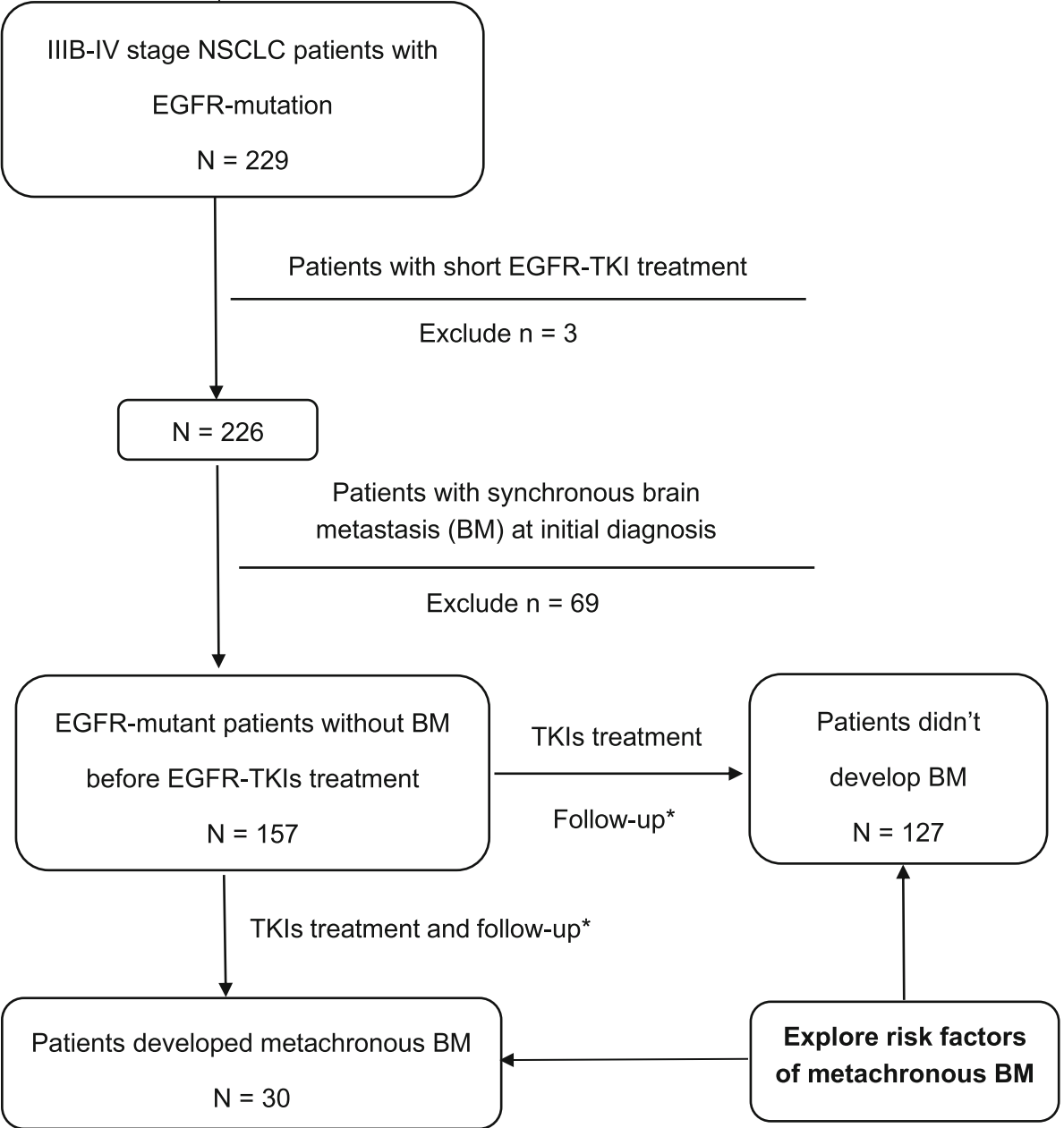

Fig. 1 Flow chart for patients' enrollment and treatment. *Follow-up examinations were performed every 2 months, including thoracic and abdominal CT scan, brain MRI scan

Cox regression analyses, and variables based on their clinical significance according to previously literature reports. The optimal cut-off values of continuous valuables were calculated by X-tile software [18]. All tests were two-sided and $P<0.05$ were considered statistically significant.

\section{Results}

Patient characteristics

The flow chart of patient enrollment was shown in Fig. 1. Between January 2012 and June 2018, Among the 229 consecutive patients with EGFR-mutated advanced NSCLC, three patients were excluded due to short 
EGFR-TKI treatment ( $<1$ month), and 69 patients were excluded due to synchronous BM. A total of 157 patients without $\mathrm{BM}$ at initial diagnosis were included: 30 patients (19.1\%) developed metachronous BM during EGFR-TKIs treatment and 127 patients (80.9\%) didn't. Among the 30 patients with metachronous BM, 20 patients $(20 / 30,66.7 \%)$ first progressed in intracranial disease, implying metachronous BM principally correlated with the ability of EGFR-TKIs to pass through $\mathrm{BBB}$.

The clinical and treatment characteristics of these patients grouped by BM status are shown in Table 1 . The median age of the patients without BM and patients developing metachronous BM was 60 and 54 years, respectively. Patients who would develop metachronous BM were more likely to have a more favorable Karnofsky Performance Status (KPS score $\geq 80: 100 \%$ patients developing metachronous $\mathrm{BM}$ vs. $90.5 \%$ patients without $\mathrm{BM})$. There was no difference between the two groups with respect to gender, histology, BMI, smoking status, tumor markers level, clinical stages, and extracranial metastatic location. In addition, it was reported that the type of EGFR mutations and were associated with OS, whereas there was no difference on the proportion of EGFR mutations type between the two groups grouped by $\mathrm{BM}$ status $\left(\mathrm{X}^{2}=3.084, P=0.214\right)$, indicating the similar distribution of EGFR mutations type had no significant impact on OS between the two groups grouped by BM status.

\section{The incidence of metachronous BM and survival}

The median duration of follow-up was 24.1 months (95\% CI: 19.6-28.6 months). Thirty patients (19.1\%) developed metachronous BM during EGFR-TKIs treatment. Among them, patients with symptomatic and asymptomatic BM were $18(60 \%)$ and $12(40 \%)$ respectively. Fourteen patients $(46.7 \%)$ received WBRT and 8 patients (26.7\%) received stereotactic radiosurgery (SRS) plus continuous EGFR-TKIs treatment, other 2 patients (6.7\%) received continuous EGFR-TKIs plus supportive care, and 6 patients (20\%) switched to chemotherapy. In addition, 9 patients $(9 / 30,30 \%)$ receiving chemotherapy as the first-line treatment developed metachronous BM during subsequent EGFR-TKIs therapy. The 1-, 2- and 3-year risks of BM were 11.6, 22.6 and $29.4 \%$ respectively (Fig. 2).

The median OS of these 157 patients was 37.5 months (95\% CI: 27.6-47.4 months). The 1-, 2- and 3-year OS rates were $86.9,69.8$ and $55.9 \%$ respectively (Fig. 2). For PFS, 105 patients (66.9\%) progressed during follow-up time. Among them, a total of 51 patients (38 of patients without BM group [38/127, 29.9\%] and 13 of patients developing metachronous BM group [13/30, 43.4\%]) finally received Osimertinib treatment after the detection of T790M mutation indicated positive by plasma or tissue rebiopsy specimens. Median PFS was 13.6 months (95\% CI:11.2-15.9 months). The 1-, 2- and 3-year PFS rates were 57.8, 29.4 and 21.3\% respectively (Fig. 2). Our median OS and PFS were longer than those of the clinical trials for patients with EGFR-mutated advanced NSCLC [19].

The overall response rates were partial for $76.4 \%$, stable for $23.0 \%$, and progressive for $0.6 \%$ of EGFR-TKIs treatment at the first follow-up examination.

\section{Overall survival of patients grouped by BM status}

To evaluate the impact of BM status on OS, the 157 patients were grouped by with metachronous BM and without BM. Compared with patients without BM, patients developing metachronous BM during the course of EGFR-TKIs treatment were at a higher risk on OS ( $\mathrm{HR}=1.86$, 95\%CI:1.07-3.26). Our findings confirmed that patients developing metachronous BM during EGFR-TKIs treatment had poorer outcomes (median OS: 22.1 months) than patients without BM (median OS: 44.8 months, Fig. 3).

\section{Risk factors of developing metachronous BM}

Several clinical factors were associated with metachronous BM in both univariate and multivariate analyses (Table 2). In univariate analyses, BM was associated with age, the first-line treatment regimens, types of EGFR mutations, numbers of extracranial metastases, and malignant pleural effusion. Other factors such as gender, KPS score, smoking status, tumor marker levels before treatment, clinical stages, types of EGFR-TKIs, and metastatic locations were not associated with metachronous BM.

The factors showing associations $(P<0.100)$ in the univariable Cox regression analyses, as well as other factors that were reported to be associated with BM in previous studies [20,21] were further examined by multivariable Cox regression analysis. Results of multivariate analysis indicated that age $\leq 49$ years $(P=$ 0.035), numbers of extracranial metastases $(P=0.013)$, and documented malignant pleural effusion $(P=$ 0.002) were independent high-risk factors of developing metachronous BM, while the first-line treatment regimens and types of EGFR mutations were not associated with metachronous BM in multivariate Cox regression analysis.

Furthermore, the 1-year actuarial incidence of developing metachronous $\mathrm{BM}$ in patients with no risk factor $(n=101), 1$ risk factor $(n=46)$, and 2 risk factors $(n=$ $10)$ were $7.01,14.61$, and $43.75 \%$, respectively $(P<0.001$, Fig. 4). Meanwhile, we performed an internal validation by randomly selecting 52 cases from our patient cohort. The 1-year actuarial incidence of developing 
Table 1 Baseline and treatment characteristics of patients grouped by BM status

\begin{tabular}{|c|c|c|c|c|}
\hline \multirow[b]{2}{*}{ Characteristic } & \multicolumn{2}{|c|}{$\begin{array}{l}\text { Patients without BM } \\
(n=127)\end{array}$} & \multicolumn{2}{|c|}{ Patients developing metachronous BM $(n=30)$} \\
\hline & NO. & $\%$ & NO. & $\%$ \\
\hline \multicolumn{5}{|l|}{ Age, years } \\
\hline$\leq 49$ & 24 & 18.9 & 12 & 40.0 \\
\hline$>49$ & 103 & 81.1 & 18 & 60.0 \\
\hline Median (Range) & $60(28-93)$ & & $54(33-75)$ & \\
\hline \multicolumn{5}{|l|}{ Gender } \\
\hline Male & 63 & 49.6 & 14 & 46.7 \\
\hline Female & 64 & 50.4 & 16 & 53.3 \\
\hline \multicolumn{5}{|l|}{ KPS score } \\
\hline$\geq 80$ & 115 & 90.5 & 30 & 100 \\
\hline$<80$ & 12 & 9.5 & 0 & 0 \\
\hline \multicolumn{5}{|l|}{ Histology } \\
\hline Adenocarcinoma & 122 & 96.1 & 28 & 93.3 \\
\hline Non-adenocarcinoma & 5 & 3.9 & 2 & 6.7 \\
\hline \multicolumn{5}{|l|}{ BMl } \\
\hline Mean $(95 \% \mathrm{Cl})$ & $21.9(14.9-28.8)$ & & $22.7(16.3-29.2)$ & \\
\hline \multicolumn{5}{|l|}{ Smoking status } \\
\hline Yes & 42 & 33.1 & 8 & 26.7 \\
\hline No & 85 & 66.9 & 22 & 73.3 \\
\hline \multicolumn{5}{|l|}{ CEA (ng/ml) } \\
\hline Median (Range) & $23.5(0.5-8048)$ & & $30.5(1.5-1819)$ & \\
\hline \multicolumn{5}{|l|}{ CA125 (ng/ml) } \\
\hline Median (Range) & $52.9(4.76-3369)$ & & $69.4(11.3-954.5)$ & \\
\hline \multicolumn{5}{|l|}{ NSE (ng/ml) } \\
\hline Median (Range) & $15.0(4.4-133.1)$ & & 15.2(7.6-55.2) & \\
\hline \multicolumn{5}{|l|}{ First-line treatment regimen } \\
\hline EGFR-TKI treatment & 112 & 88.2 & 21 & 70 \\
\hline Chemotherapy & 15 & 11.8 & 9 & 30 \\
\hline \multicolumn{5}{|l|}{ Type of EGFR mutations } \\
\hline L858R & 49 & 38.6 & 14 & 46.7 \\
\hline 19 deletion & 67 & 52.8 & 11 & 36.7 \\
\hline Other $^{a}$ & 11 & 8.6 & 5 & 16.7 \\
\hline \multicolumn{5}{|c|}{ NO. of extracranial metastases } \\
\hline 0 & 8 & 6.3 & 2 & 6.7 \\
\hline 1 & 65 & 51.2 & 14 & 46.7 \\
\hline 2 & 42 & 33.1 & 10 & 33.3 \\
\hline 3 or more & 12 & 9.4 & 4 & 13.3 \\
\hline \multicolumn{5}{|l|}{ Clinical stages } \\
\hline Stage IIIB & 8 & 6.3 & 2 & 6.7 \\
\hline Stage IV & 119 & 93.7 & 28 & 93.3 \\
\hline \multicolumn{5}{|c|}{ Location of extracranial metastatic sites } \\
\hline Pleural effusion & 8 & 6.3 & 6 & 20.0 \\
\hline Liver & 17 & 13.4 & 4 & 13.3 \\
\hline
\end{tabular}


Table 1 Baseline and treatment characteristics of patients grouped by BM status (Continued)

\begin{tabular}{|c|c|c|c|c|}
\hline \multirow[b]{2}{*}{ Characteristic } & \multicolumn{2}{|c|}{$\begin{array}{l}\text { Patients without BM } \\
(n=127)\end{array}$} & \multicolumn{2}{|c|}{ Patients developing metachronous BM $(n=30)$} \\
\hline & NO. & $\%$ & NO. & $\%$ \\
\hline Adrenal & 17 & 13.4 & 1 & 3.3 \\
\hline Bone & 73 & 57.5 & 18 & 60 \\
\hline Lung & 75 & 59.1 & 17 & 56.6 \\
\hline Other & 12 & 9.4 & 2 & 6.7 \\
\hline \multicolumn{5}{|c|}{ Types of EGFR-TKls } \\
\hline Gefitinib & 80 & 63.0 & 19 & 63.3 \\
\hline Erlotinib & 31 & 24.4 & 7 & 23.3 \\
\hline Icotinib & 16 & 12.6 & 4 & 13.4 \\
\hline \multicolumn{5}{|c|}{ Local therapy for BM } \\
\hline None & NA & & 8 & 26.7 \\
\hline WBRT & NA & & 14 & 46.7 \\
\hline SRS & NA & & 8 & 26.6 \\
\hline
\end{tabular}

Abbreviation: BM brain metastasis, KPS Karnofsky Performance Status, Cl confidence interval, EGFR epidermal growth factor receptor, WBRT whole brain radiation therapy, SRS stereotactic radiosurgery, NSE neuron-specific enolase, TKI tyrosine kinase inhibitor

aUncommon EGFR mutations, including 20-ins (7 pts), G719X (3 pts), L816Q (2 pts), G863D (1 pt), K846R (1 pt), V765A (2 pts)

metachronous $\mathrm{BM}$ in these 52 patients with no risk factor $(n=37), 1$ risk factor $(n=11)$, and 2 risk factors $(n=$ 4) were $5.65,22.2$, and $50.0 \%$, respectively $(P=0.004$, Figure S1). These results were consistent with the whole cohort, indicating the credibility of the result to some extent. Therefore, patients with more risk factors had higher risk of developing metachronous BM. Our studies suggested that the patients with $\geq 1$ risk factors were more likely to benefit from PCI or the first-line Osimertinib treatment.

\section{Discussion}

EGFR mutations are observed in approximately $10-15 \%$ of the Caucasian population [22] and more than $50 \%$ of the Asian population [23] with non-squamous NSCLC. During the past two decades, the advances of EGFRTKIs revolutionarily improved the prognosis of patients with EGFR-mutated advanced NSCLC. The WJTOG3405 trial reported that the median OS of EGFR-mutated advanced NSCLC patients treated with first-generation EGFR-TKI was up to 30.2 months [24].

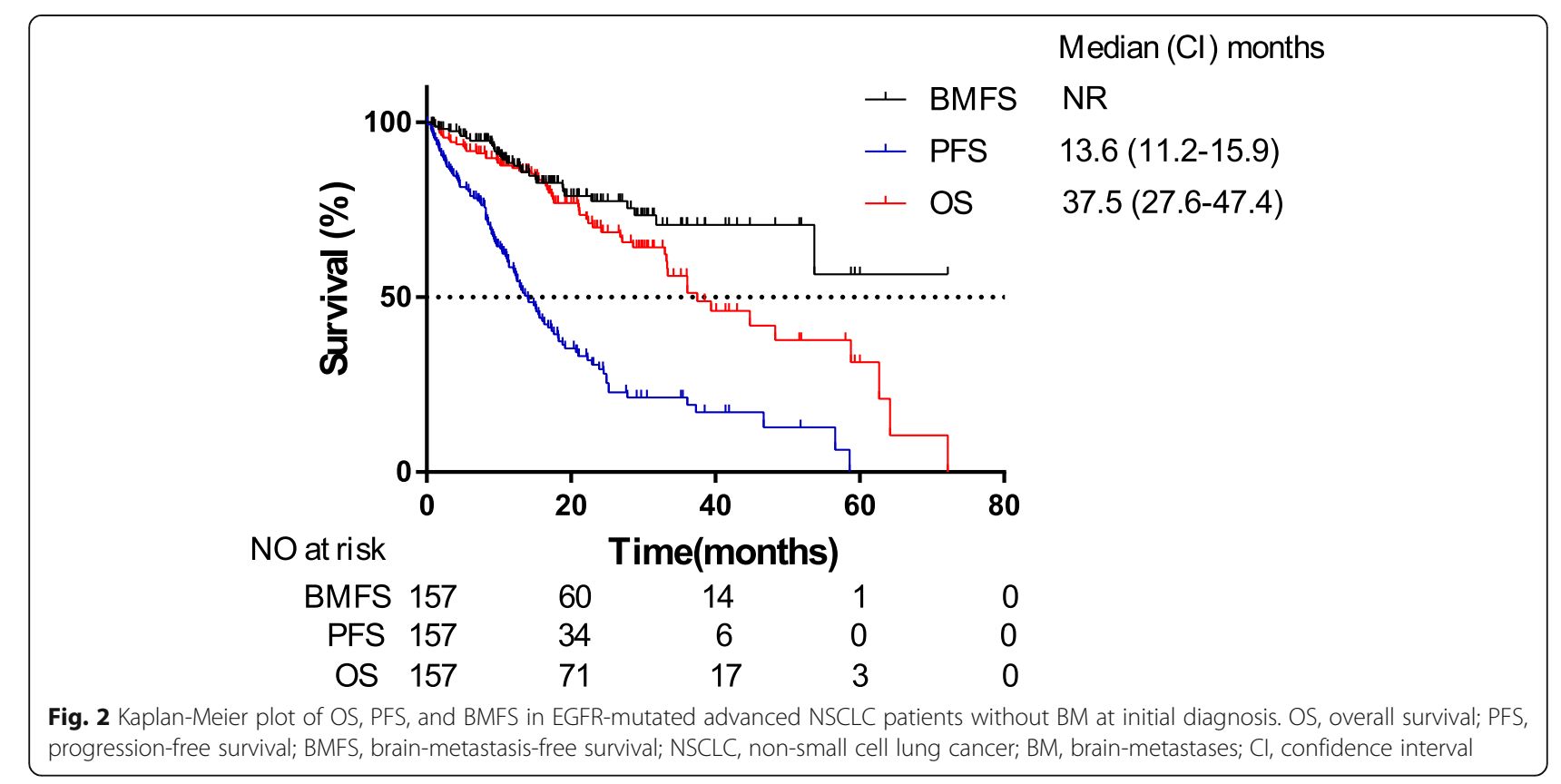




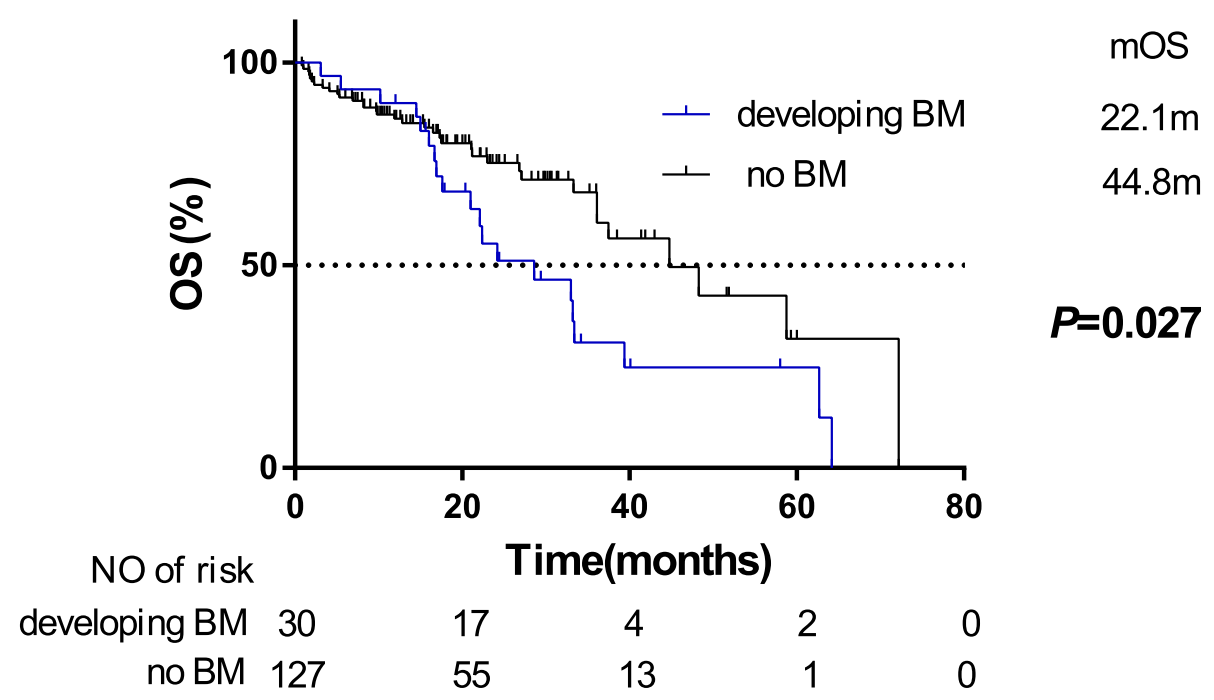

Fig. 3 Kaplan-Meier plot of OS in patients with EGFR-mutated advanced NSCLC grouped on BM status. OS, overall survival; NSCLC, non-small cell lung cancer; BM, brain-metastases; $\mathrm{Cl}$, confidence interval

Our results of 157 EGFR-mutated advanced NSCLC patients without BM at initial diagnosis also showed a median OS of 37.5 months (Fig. 2). Compared with chemotherapy, although EGFR-TKIs were reported to pass through $\mathrm{BBB}$ and reduce $\mathrm{BM}$ among EGFRmutated NSCLC patients $[25,26]$, there remain some patients developing metachronous BM during the course of EGFR-TKIs therapy. Lee et al. found that $26 \%$ of the patients developed central nervous system (CNS) failure and 13\% experienced isolated CNS failure among 166 patients with a clinical benefit to first-generation EGFRTKIs (gefitinib or erlotinib) treatment [27]. In our study, 30 patients $(30 / 157,19.1 \%)$ developed metachronous BM during first-generation EGFR-TKIs treatment, and 1-, 2- and 3-year risks of developing BM were 11.6, 22.6 and $29.4 \%$ respectively (Fig. 2). Moreover, patients with longer survival exposed to a higher risk of BM [9]. Therefore, the first-generation EGFR-TKIs therapy resulted in decreased risk of non-BM lesions but had limited impact on BM.

It was well known that $\mathrm{BM}$ is a common reason leading to treatment failure [28]. In our study, compared with patients without BM, patients developing metachronous BM during the course of first-generation EGFR-TKIs treatment were at a higher risk on OS (HR = 1.86, 95\%CI:1.07-3.26) (Fig. 3), which was on the condition that there was no difference on clinical and treatment characteristics between the two groups grouped by BM status (Table 1). Among these clinical and treatment characteristics, it was reported that the type of EGFR mutation was associated with OS. And the median OS of our patients with L858R, 19-del, and uncommon EGFR mutations was 38.1 months, 45.1 months, and 24.1 months, respectively $(P=0.026)$. However, there was no difference on the proportion of EGFR mutation type between the two groups grouped by BM status $\left(\chi^{2}=3.084, P=0.214\right)$, indicating the similar distribution of EGFR mutation type had no significant impact on OS between the two groups. Therefore, reducing incidence of BM in EGFR-mutated advanced NSCLC patients becomes increasingly significant to achieve prolonged survival.

The use of PCI or the first-line Osimertinib treatment could reduce incidence of metachronous BM among EGFR-mutated advanced NSCLC patients. However, existing evidences suggest that PCI might just suitable for patients with high risk of developing $\mathrm{BM}$, and the high cost of Osimertinib leaded to the limitation of first-line Osimertinib treatment in most developing countries. Therefore, it is important to identify population subsets with higher risk of BM as candidates for PCI or the first-line Osimertinib treatment. Previous studies identified several risk factors of BM in NSCLC, including younger age [29-31], non-squamous cell carcinoma [29], high serum CEA level [20], and disease stages [30, 32]. However, they were not specific for EGFR-mutated advanced NSCLC patients, and synchronous $\mathrm{BM}$ at initial diagnosis and metachronous BM during their disease course are seldom differentiated in these reports.

In our current study, multivariate analysis indicated that age $\leq 49$ years was correlated with higher risk of metachronous BM (Table. 2). Despite the difference of age cut-off, our results were consistent with previous studies [30,33]. The underlying mechanism remains unclear. It was partly interpreted that young people may have better performance status, which is associated with longer survival, leading to higher risk of exposure to 
Table 2 Univariate and multivariate analyses for the factors associated with risks for metachronous BM

\begin{tabular}{|c|c|c|c|c|c|c|}
\hline \multirow[t]{2}{*}{ Factors } & \multicolumn{3}{|c|}{ Univariate analysis Incidence of BM (\%) } & \multicolumn{3}{|c|}{ Multivariate analysis Incidence of BM (\%) } \\
\hline & $\mathrm{HR}$ & $95 \% \mathrm{Cl}$ & $P$ & $\mathrm{HR}$ & $95 \% \mathrm{Cl}$ & $P$ \\
\hline Gender: female VS male & 1.139 & $0.556-2.337$ & 0.772 & 1.495 & $0,506-4.421$ & 0.467 \\
\hline Age, years & 0.963 & $0.931-0.995$ & 0.023 & & & \\
\hline$>49$ VS $\leq 49$ & 0.341 & $0.162-0.720$ & 0.005 & 0.396 & $0.167-0.938$ & 0.035 \\
\hline KPS score: $<80$ VS $\geq 80$ & 0.045 & $0.000-40.173$ & 0.371 & & & \\
\hline BMl & 1.035 & $0.922-1.161$ & 0.562 & 1.057 & $0.919-1.216$ & 0.436 \\
\hline Smoking: yes VS no & 0.798 & $0.353-1.801$ & 0.586 & 1.302 & $0.384-4.408$ & 0.672 \\
\hline \multicolumn{7}{|c|}{ Tumor markers level before treatment } \\
\hline CEA (ng/ml) & 1.000 & $0.999-1.000$ & 0.685 & 1.000 & $0.999-1.000$ & 0.294 \\
\hline CA125 (ng/ml) & 1.000 & $0.998-1.001$ & 0.498 & & & \\
\hline NSE (ng/ml) & 1.014 & $0.985-1.043$ & 0.351 & & & \\
\hline \multicolumn{7}{|l|}{ First-line treatment regimen } \\
\hline Chemotherapy VS EGFR-TKI & 2.296 & $1.050-5.018$ & 0.037 & 0.504 & $0.153-1.660$ & 0.260 \\
\hline Type of EGFR mutations & & & 0.071 & & & 0.061 \\
\hline 19-del VS L858R & 0.579 & $0.263-1.277$ & 0.176 & 0.490 & $0.201-1.194$ & 0.116 \\
\hline Other ${ }^{\mathrm{a}}$ VS L858R & 1.968 & $0.703-5.508$ & 1.968 & 2.408 & $0.566-10.246$ & 0.234 \\
\hline Clinical stages: IIIB VS. IV & 0.501 & $0.152-1.653$ & 0.257 & & & \\
\hline Type of EGFR-TKls & & & 0.262 & & & \\
\hline Erlotinib VS Gefitinib & 0.422 & $0.118-1.503$ & 0.183 & & & \\
\hline Icotinib VS Gefitinib & 0.460 & $0.109-1.946$ & 0.292 & & & \\
\hline \multicolumn{7}{|l|}{ NO. of extracranial metastasis } \\
\hline $0-2$ VS 3 or more & 0.523 & $0.181-1.514$ & 0.232 & 0.200 & $0.056-0.713$ & 0.013 \\
\hline \multicolumn{7}{|l|}{ Location of extracranial metastasis } \\
\hline Pleural effusion & 3.245 & $1.300-8.098$ & 0.012 & 5.283 & $1.854-15.053$ & 0.002 \\
\hline Liver & 1.066 & $0.371-3.062$ & 0.906 & & & \\
\hline Adrenal & 0.242 & $0.033-1.779$ & 0.163 & & & \\
\hline Bone & 1.161 & $0.558-2.413$ & 0.690 & & & \\
\hline Lung & 1.543 & $0.685-3.475$ & 0.295 & & & \\
\hline Other & 1.332 & $0.317-5.605$ & 0.696 & & & \\
\hline
\end{tabular}

Abbreviation: BM brain metastasis, KPS Karnofsky Performance Status, $C l$ confidence interval, EGFR epidermal growth factor receptor, WBRT whole brain radiation therapy, SRS stereotactic radiosurgery, NSE neuron-specific enolase, TKI tyrosine kinase inhibitor

a Uncommon EGFR mutations, including 20-ins (7 pts), G719X (3 pts), L816Q (2 pts), G863D (1 pt), K846R (1 pt), V765A (2 pts)

BM. Moreover, several studies have shown that BM is associated with the angiogenic microenvironment, and the cerebrovascular microenvironment factors of young patients may be better than those of older patients [34]. Further investigations are required to identify the specific mechanism that younger patients are more likely to develop BM.

The numbers of malignant pleural effusion and extracranial metastases were also independent risk factors of metachronous BM (Table. 2). The underlying mechanism was also unclear. It may be interpreted that both pleural effusion and $\mathrm{BM}$ is associated with the angiogenic microenvironment [34]. In addition, the numbers of extracranial metastases are reflection of tumor burden, which was positive correlated with the development of BM.

Furthermore, our results confirmed that the predictive value of gender and KPS score for metachronous BM may remain controversial [35]. Previous studies reported that elevated CEA [20, 21, 35], NSE [29], and CA125 [29] were independent risk factors of BM. However, there is no correlation between tumor markers levels before treatment (including CEA, NSE, and CA125) and the metachronous $\mathrm{BM}$ in our study. And the first-line treatment regimen was also not associated with metachronous BM in our multivariate Cox analysis. In addition, a recent retrospective study [21] also showed that point mutations in exon 21 were independent risk 


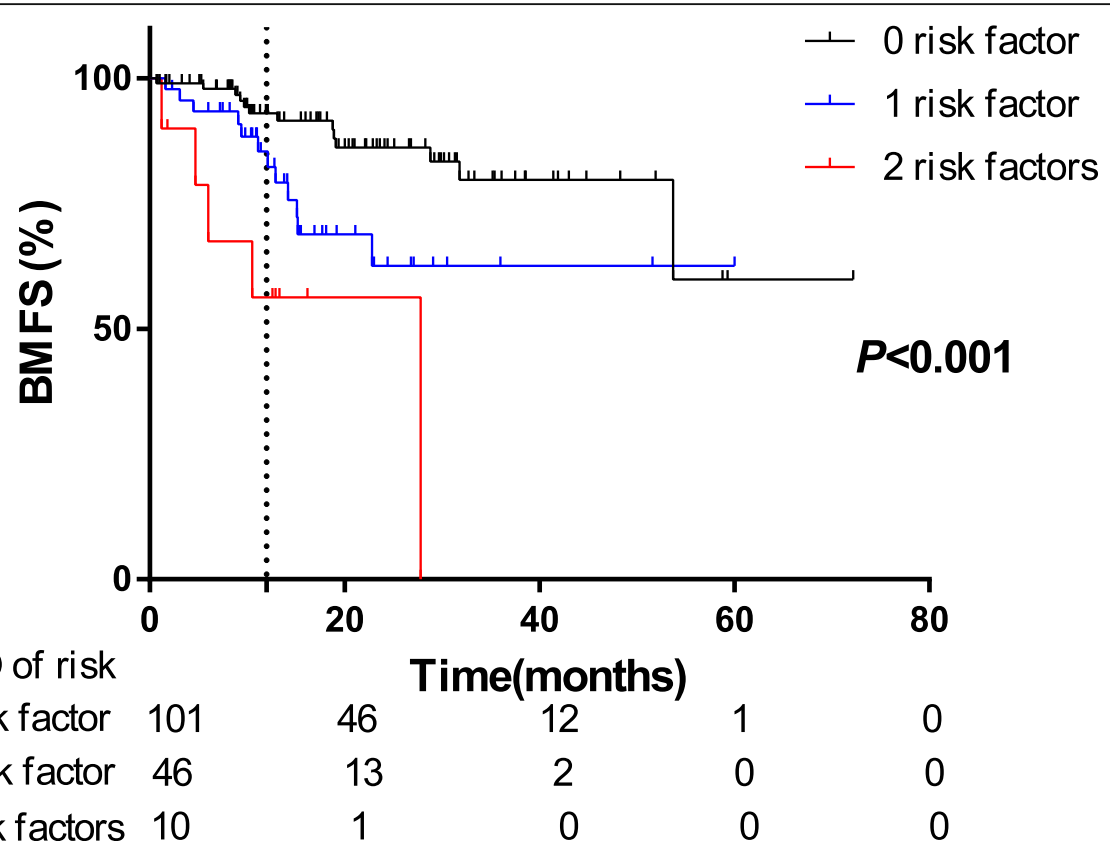

Fig. 4 Comparison of the actuarial risk of developing metachronous BM among patients with different numbers of risk factors

factors of BM. However, our results failed to show a statistical difference in the association between types of EGFR mutations and metachronous BM.

Finally, the 1-year actuarial risk of developing metachronous $\mathrm{BM}$ in patients with no risk factor $(n=101), 1$ risk factor $(n=46)$, and 2 risk factors $(n=10)$ were $7.01,14.61$, and $43.75 \%$, respectively $(P<0.001$, Fig. 4). Obviously, patients with more risk factors had higher risk of developing metachronous BM. Our studies suggested that the patients with $\geq 1$ risk factors were more likely to benefit from PCI or were candidates for the first-line Osimertinib treatment. Certainly, there are several limitations in our study, this was a retrospective study in a single institution, which inevitably resulted in a selection bias. More finely devised prospective and random study is needed to confirm our results, and the mechanisms of the correlation between these risk factors and metachronous BM are to be further explored.

\section{Conclusions}

Collectively, the findings of this study were as follows. First, our study confirmed EGFR-mutated advanced NSCLC patients with metachronous BM had worse outcomes. Second, the multivariate Cox analysis indicated that younger age ( $\leq 49$ years), more extracranial metastases, and malignant pleural effusion were independent risk factors of metachronous BM. Third, the patients with more risk factors were more likely to benefit from PCI or the first-line Osimertinib treatment.

\section{Supplementary information}

Supplementary information accompanies this paper at https://doi.org/10. 1186/s12885-020-07202-8

Additional file 1: Figure S1. Comparison of the actuarial risk of developing metachronous BM among randomly select 52 cases from our patient cohort grouped by different numbers of risk factors.

\section{Abbreviations}

BM: Brain metastasis; PCl: Prophylactic cranial irradiation; BBB: Blood-brain barrier; Cl: Confidence interval; EGFR: Epidermal growth factor receptor; NSCL C: Non-small cell lung cancer; SCLC: Small cell lung cancer; WBRT: Whole brain radiation therapy; SRS: Stereotactic radiosurgery; CNS: Central nervous system; NGS: Next Generation Sequencing; NSE: Neuron-specific enolase; DFS: Disease free survival; OS: Overall survival; PD: Progression of disease; PFS: Progression-free survival; BMFS: Brain-metastasis-free survival; CR: Complete response; PR: Partial response; SD: Stable; TKI: Tyrosine kinase inhibitor; VEGF: Vascular endothelial growth factor

\section{Acknowledgements}

None

Authors' contributions

Conception and design of the work: WO, JY and CX. Acquisition, analysis and interpretation of data: $W O, Y Z, J Y, J H$ and $Z H$. Drafting and revising of the article: WO, JZ and CX. Final approval of the manuscript and agreement to be accountable for all aspects of the work: All authors.

\section{Funding}

This study was supported by grants from the National Natural Science Foundation of China (No. 81502308 and 81773236). The funding bodies had no role on the design, data collection, analysis and manuscript writing of this study.

Availability of data and materials

The datasets used and analyzed in the current study are available from the corresponding author upon reasonable request. 


\section{Ethics approval and consent to participate}

This study was approved by the Ethics Committee of Zhongnan hospital of Wuhan University. Ethics Committee approved verbal informed consent. Because our study is retrospective, and we collected and analyzed the data of enrolled patients by reviewing their electronic medical records. The information of enrolled patients is anonymous. The collection, analysis and publication of the data will not infringe enrolled patients' health, safety and privacy. Informed consent was obtained orally from the included patients by telephone.

\section{Consent for publication}

Not applicable.

\section{Competing interests}

The authors declare that they have no competing interests.

\section{Author details}

'Department of Radiation and Medical Oncology, Zhongnan Hospital of Wuhan University, 169 Donghu Road, Wuchang District, Wuhan 430071, Hubei, China. ${ }^{2}$ Hubei Key Laboratory of Tumor Biological Behaviors, Zhongnan Hospital of Wuhan University, Wuhan, China. ${ }^{3}$ Hubei Clinical Cancer Study Center, Zhongnan Hospital of Wuhan University, Wuhan, China.

Received: 14 November 2019 Accepted: 21 July 2020

Published online: 28 July 2020

\section{References}

1. Govindan R, Page N, Morgensztern D, et al. Changing epidemiology of small-cell lung cancer in the United States over the last 30 years: analysis of the surveillance, epidemiologic, and end results database. J Clin Oncol 2006; 24:4539-4544. https://doi.org/https://doi.org/10.1200/JCO.2005.04.4859.

2. Saad AG, Yeap BY, Thunnissen FB, et al. Immunohistochemical markers associated with brain metastases in patients with nonsmall cell lung carcinoma. Cancer. 2008;113:2129-2138. https://doi.org/https://doi.org/10. 1002/cncr.23826

3. Lin NU, Wefel JS, Lee EQ, et al. Challenges relating to solid tumour brain metastases in clinical trials, part 2: neurocognitive, neurological, and qualityof-life outcomes. A report from the RANO group. Lancet Oncol2013;14: e407-e416. https://doi.org/https://doi.org/10.1016/S1470-2045(13)70308-5.

4. Kepka L, Cieslak E, Bujko K, et al. Results of the whole-brain radiotherapy for patients with brain metastases from lung cancer: the RTOG RPA intra-classes analysis. Acta Oncol 2005;44:389-398. https://doi.org/https://doi.org/10. 1080/02841860510029699.

5. Maemondo M, Inoue A, Kobayashi K, et al. Gefitinib or chemotherapy for non-small-cell lung cancer with mutated EGFR. N Engl J Med 2010;362: 2380-2388. https://doi.org/https://doi.org/10.1056/NEJMoa0909530.

6. Mok TS, Wu Y-L, Ahn M-J, et al. Osimertinib or platinum-Pemetrexed in EGFR T790M-positive lung Cancer. N Engl J Med 2017;376:629-640. https:// doi.org/https://doi.org/10.1056/NEJMoa1612674.

7. Soria JC, Ohe Y, Vansteenkiste J, et al. Osimertinib in untreated EGFRmutated advanced non-small-cell lung Cancer. N Engl J Med 2018;378:113125. https://doi.org/https://doi.org/10.1056/NEJMoa1713137.

8. Sperduto PW, Yang TJ, Beal K, et al. The effect of gene alterations and tyrosine kinase inhibition on survival and cause of death in patients with adenocarcinoma of the lung and brain metastases. Int J Radiat Oncol Biol Phys 2016;96:406-413. https://doi.org/https://doi.org/10.1016/j.ijrobp.2016. 06.006.

9. Han G, Bi J, Tan W, et al. A retrospective analysis in patients with EGFRmutant lung adenocarcinoma: is EGFR mutation associated with a higher incidence of brain metastasis?. Oncotarget. 2016;7:56998-57010. https://doi. org/https://doi.org/10.18632/oncotarget.10933.

10. Bhatt VR, D'Souza SP, Smith LM, Cushman-Vokoun AM, Noronha V, Verma V, et al. Epidermal growth factor receptor mutational status and brain metastases in non-small-cell lung Cancer. J Glob Oncol 2016;3:208-217. https://doi.org/https://doi.org/10.1200/JGO.2016.003392.

11. Fan $Y, X u X$, Xie C. EGFR-TKI therapy for patients with brain metastases from non-small-cell lung cancer: a pooled analysis of published data. Onco Targets Ther 2014;7:2075-2084. https://doi.org/https://doi.org/10.2147/OTT. S67586.

12. Komaki R, Scott CB, Byhardt $R$, et al. Failure patterns by prognostic group determined by recursive partitioning analysis (RPA) of 1547 patients on four radiation therapy oncology group (RTOG) studies in inoperable nonsmallcell lung cancer (NSCLC). Int J Radiat Oncol Biol Phys 1998;42:263-267. https://doi.org/https://doi.org/10.1016/S0360-3016(98)00213-2.

13. Gore EM, Bae K, Wong SJ, et al. Phase III comparison of prophylactic cranial irradiation versus observation in patients with locally advanced non-smallcell lung cancer: primary analysis of radiation therapy oncology group study RTOG 0214. J Clin Oncol 2011;29:272-278. https://doi.org/https://doi.org/10. 1200/JCO.2010.29.1609.

14. Sun A, Bae K, Gore EM, et al. Phase III trial of prophylactic cranial irradiation compared with observation in patients with locally advanced non-small-cell lung cancer: neurocognitive and quality-of-life analysis. J Clin Oncol 2011;29: 279-286. https://doi.org/https://doi.org/10.1200/JCO.2010.29.6053.

15. Cross DA, Ashton SE, Ghiorghiu S, et al. AZD9291, an irreversible EGFR TKI, overcomes T790M-mediated resistance to EGFR inhibitors in lung cancer. Cancer Discov 2014;4:1046-1061. https://doi.org/https://doi.org/10.1158/ 2159-8290.cd-14-0337.

16. Ballard P, Yates JW, Yang Z, et al. Preclinical comparison of Osimertinib with other EGFR-TKIs in EGFR-mutant NSCLC brain metastases models, and early evidence of clinical brain metastases activity. Clin Cancer Res 2016;22:51305140. https://doi.org/https://doi.org/10.1158/1078-0432.ccr-16-0399.

17. Vansteenkiste J, Reungwetwattana T, Nakagawa K, et al. CNS response to osimertinib vs standard of care (SoC) EGFR-TKI as first-line therapy in patients (pts) with EGFR-TKI sensitising mutation (EGFRm)-positive advanced non-small cell lung cancer (NSCLC): data from the FLAURA study. Ann Oncol 2017;28. https://doi.org/https://doi.org/10.1093/annonc/mdx729.007.

18. Camp RL, Dolled-Filhart M, Rimm DL. X-tile: a new bio-informatics tool for biomarker assessment and outcome-based cut-point optimization. Clin Cancer Res 2004;10:7252-7259. https://doi.org/https://doi.org/10.1158/10780432.CCR-04-0713.

19. Roeper J, Griesinger F. Epidermal growth factor receptor tyrosine kinase inhibitors in advanced nonsmall cell lung cancer: what is the preferred firstline therapy?. Curr Opin Oncol $2019 ; 31: 1-7$. https://doi.org/https://doi.org/ 10.1097/CCO.0000000000000495.

20. Arrieta $O$, Saavedra-Perez D, Kuri R, et al. Brain metastasis development and poor survival associated with carcinoembryonic antigen (CEA) level in advanced non-small cell lung cancer: a prospective analysis. BMC Cancer 2009;9:119. https://doi.org/https://doi.org/10.1186/1471-2407-9-119.

21. Ma X, Zhu H, Guo H, et al. Risk factors of brain metastasis during the course of EGFR-TKIs therapy for patients with EGFR-mutated advanced lung adenocarcinoma. Oncotarget. 2016;7:81906-81917. https://doi.org/https:// doi.org/10.18632/oncotarget.11918.

22. Barlesi F, Mazieres J, Merlio JP, et al. Biomarkers France contributors. Routine molecular profiling of patients with advanced non-small-cell lung cancer: results of a 1-year nationwide programme of the French cooperative thoracic intergroup (IFCT). Lancet. 2016;387:1415-1426. https://doi.org/ https://doi.org/10.1016/S0140-6736(16)00004-0.

23. Mok TS, Wu YL, Thongprasert S, et al. Gefitinib or carboplatin-paclitaxel in pulmonary adenocarcinoma. N Engl J Med 2009;361:947-957. https://doi. org/https://doi.org/10.1056/NEJMoa0810699.

24. Mitsudomi T, Morita S, Yatabe Y, et al. Gefitinib versus cisplatin plus docetaxel in patients with non-small-cell lung cancer harbouring mutations of the epidermal growth factor receptor (WJTOG3405): an open label, randomised phase 3 trial. Lancet Oncol 2010;11:121-128. https://doi.org/ https://doi.org/10.1016/S1470-2045(09)70364-X.

25. Wu YL, Zhou C, Cheng Y, et al. Erlotinib as second-line treatment in patients with advanced non-small-cell lung cancer and asymptomatic brain metastases: a phase II study (CTONG-0803). Ann Oncol 2013;24:993-999. https://doi.org/https://doi.org/10.1093/annonc/mds529.

26. Weber B, Winterdahl M, Memon A, et al. Erlotinib accumulation in brain metastases from non-small cell lung cancer: visualization by positron emission tomography in a patient harboring a mutation in the epidermal growth factor receptor. J Thorac Oncol 2011;6:1287-1289. https://doi.org/ https://doi.org/10.1097/JTO.0b013e318219ab87.

27. Lee YJ, Choi HJ, Kim SK, et al. Frequent central nervous system failure after clinical benefit with epidermal growth factor receptor tyrosine kinase inhibitors in Korean patients with non small-cell lung cancer. Cancer. 2010; 116:1336-1343. https://doi.org/https://doi.org/10.1002/cncr.24877.

28. Arrieta O, Villarreal-Garza C, Zamora J, et al. Long-term survival in patients with non-small cell lung cancer and synchronous brain metastasis treated with whole-brain radiotherapy and thoracic chemoradiation. Radiat Oncol 2011;6:166. https://doi.org/https://doi.org/10.1186/1748-717X-6-166. 
29. Ji Z, Bi N, Wang J, et al. Risk factors for brain metastases in locally advanced non-small cell lung cancer with definitive chest radiation. Int J Radiat Oncol Biol Phys 2014;89:330-337. https://doi.org/https://doi.org/10.1016/j.jirobp. 2014.02.025.

30. Ceresoli GL, Reni M, Chiesa G, et al. Brain metastases in locally advanced nonsmall cell lung carcinoma after multimodality treatment: risk factors analysis. Cancer. 2002;95:605-612. https://doi.org/https://doi.org/10.1002/ cncr.10687.

31. Gaspar LE, Chansky K, Albain KS, et al. Time from treatment to subsequent diagnosis of brain metastases in stage III non-small-cell lung cancer: a retrospective review by the southwest oncology group. J Clin Oncol 2005; 23:2955-2961. https://doi.org/https://doi.org/10.1200/JCO.2005.08.026.

32. Robnett TJ, Machtay M, Stevenson JP, et al. Factors affecting the risk of brain metastases after definitive chemoradiation for locally advanced nonsmall-cell lung carcinoma. J Clin Oncol 2001;19:1344-1349. https://doi.org/ https://doi.org/10.1200/JCO.2001.19.5.1344.

33. Dimitropoulos C, Hillas G, Nikolakopoulou S, et al. Prophylactic cranial irradiation in non-small cell lung cancer patients: who might be the candidates?. Cancer Manag Res 2011;3:287-294. https://doi.org/https://doi. org/10.2147/CMR.S22717.

34. Cedrés $S$, Nuñez I, Longo $M$, et al. Serum tumor markers CEA, CYFRA21-1, and CA-125 are associated with worse prognosis in advanced non-small-cell lung cancer (NSCLC). Clin Lung Cancer 2011;12:172-179. https://doi.org/ https://doi.org/10.1016/..cllc.2011.03.019.

35. An N, Jing W, Wang $H$, et al. Risk factors for brain metastases in patients with non-small-cell lung cancer. Cancer Med 2018;7:6357-6364. https://doi. org/https://doi.org/10.1002/cam4.1865.

\section{Publisher's Note}

Springer Nature remains neutral with regard to jurisdictional claims in published maps and institutional affiliations.

Ready to submit your research? Choose BMC and benefit from:

- fast, convenient online submission

- thorough peer review by experienced researchers in your field

- rapid publication on acceptance

- support for research data, including large and complex data types

- gold Open Access which fosters wider collaboration and increased citations

- maximum visibility for your research: over $100 \mathrm{M}$ website views per year

At $\mathrm{BMC}$, research is always in progress.

Learn more biomedcentral.com/submissions 